\title{
Analysis of Fundus Photography and Fluorescein Angiography in Chinese patients with different stages of non-arteritic anterior inschemic optic neuropathy
}

\section{Liping Wang}

Chinese PLA General Hospital

Ying Li ( $\sim$ liying_0131@sina.com )

\section{Research article}

Keywords: Non-arteritic anterior inschemic optic neuropathy, Fundus Photography, Fluorescein Aniography

Posted Date: August 15th, 2019

DOl: https://doi.org/10.21203/rs.2.13076/v1

License: (9) This work is licensed under a Creative Commons Attribution 4.0 International License. Read Full License 


\section{Abstract}

ABSTRACT Purpose: The aim of this study was to characterize the different stages of non-arteritic anterior inschemic optic neuropathy (NAION) features by Fundus Photography (FP) and Fluorescein Aniography (FA) in a Chinese Population. Methods: The retrospective observation study included 30 patients (36 eyes) with acute phase, 20 patients (27 eyes) with subacute phase and 30 patients (52 eyes) with chronic phase. Macular, optic nerve and disc were investigated by FP and FA. Categorical variables were evaluated by Fisher's exact test. Results: Macular edema, papilloedema, disc hemorrhage and exudation from FP were more common in the acute and subacute stage groups than chronic stage group with optic atrophy in contrast (all $p<0.01$ ). Compared to chronic stage, acute and subacute stages were more likely to appear macular fluorescence accumulation and peripapillary choroid filling delay (all $p<0.01$ ). However, chronic stage tended to have retinal artery filling delay and disc filling defects in the early phase from FA (all $p<0.01)$. Conclusion: The data showed that NAION had different fundus performances at different clinical stages. They may help to record the disease progression for accurate diagnosis and treatment.

\section{Background}

Non-arteritic anterior inschemic optic neuropathy (NAION) is the most common form of acute optic neuropathies among the middle-aged and elderly population with the annual incidence of 2.3 to 11.4 per 10000 persons ${ }^{1,2}$. NAION is characterized by sudden, painless, monocular vision loss and visual field defects with edema of the optic disc. The most important anatomic factor of NAION is small cups with crowded optic nerve and small cup-to-disc ratio ${ }^{3}$. However, it is difficult to see when the optic disc is swollen. Acute hypoperfusion of posterior ciliary arteries is the primary trigger of $\mathrm{NAION}^{4}$. Therefore, the degree of ischemia in the optic-nerve head could be a new way to understand the pathogenesis of NAION for further diagnosis and treatment.

Fundus Photography (FP) and Fluorescein Aniography (FA) have become more common in the evaluation and management of patients with optic neuropathies, such as NAION. Although disc edema and peripapillary hemorrhages by FP could be suggestive in the diagnosis of NAION, it may be insignificant in cases without definite features ${ }^{5}$. FA can provide dynamic information about chorioretinal circulation to quantify unique vascular features such as central retinal artery and posterior ciliary arteries.

For these reasons, FA has become a widely used technique to detect the morphological features of NAION. Delayed optic disc filling and localized peripapillary choroid filling delays are typical characteristics of $\mathrm{NAION}^{6,7}$. Arnold AC et al. reported that optic disc filling delay is common in NAION, instead of a feature of nonischemic optic optic disc edema ${ }^{6}$. KO MK et al. found different types of choroidal filling delay in NAION ${ }^{7}$. Ungsoo SK compared the difference between NAION and optic neuritis (ON) by FA ${ }^{8}$. However, few published reports focus the different clinical stages of NAION. Therefore, we compared the features of different stages in NAION patient to provide a strong evidence for further diagnosis and treatment.

\section{Methods}

Our study is a retrospective observational study reviewing hospitalized patients who were diagnosed with NAION in the Neuro-Ophthalmology Department of Chinese People's Liberation Army General Hospital (PLAGH). 
The institutional ethics committee in PLAGH approved this study. Helsinki Declaration was performed in adherence with the tenets. All subjects written were informed consent.

\section{Patients}

Patients were recruited between December 2012 and December 2018. We performed full ophthalmologic examinations including systematic neuro-ophthalmologic history collection, best-corrected visual acuity, slitlamp examination, pupillary reaction, visual field inspection, electrophysiological examination and other fundus examinations. The diagnosis of NAION was defined clinically: (1) painless rapid loss of visual acuity, (2) relative afferent pupillary defect, (3) characteristic visual field defect, (4) apparent nerve changes in the fundus. Patients were excluded with any following conditions: (1) arteritic anterior ischemic optic neuropathy (AION), (2) other diseases that cause optic neuropathy, such as toxic and traumatic optic neuropathy, (3) history of other ocular diseases, such as glaucoma and retinal diseases, (4) systemic diseases, such as tumor and epilepsy, (5) severe turbidity of refractive media and difficulty in cooperation with FA examination.

\section{FP and FA examination}

FP and FA examination was performed using a digital fundus camera (Kowa Nonmyd 7, Japan; HRA spectralis, Heidelberg engineering, Germany) according to the standard protocols. In the FP, macular edema, optic atrophy, papilloedema, disc hemorrhage and exudation were compared among different clinical stages of NAION. The non-affected eye was investigated as well. In the FA, we recorded the whole process of optic disc fluorescence filling, and performed comprehensive imaging recording of binocular optic nerve and retina. The macular fluorescence accumulation, peripapillary choroid filling delay, disc filling defects and retinal artery filling delay were focused during the whole process.

\section{Statistical Analyses}

All statistical analyses were performed using Graph Pad Prism Software (GraphPad Software Inc., USA). Categorical variables were evaluated by Fisher's exact test. $P<0.05$ was considered statistically significant.

\section{Results}

\section{Clinical Characteristics}

Final analyses enrolled 80 patients (32 men and 48 women) including 113 eyes. The mean age of this study is $64.26 \pm 8.12$ (40-80 years). According to the onset time, this study was divided into three groups: acute stage group (<1 month), subacute stage group (1-6 months) and chronic stage group( $>6$ months). Acute stage group contains 30 patients with 6 patients (20.00\%) experienced bilateral involvement (Table 1). Among 20 patients in the subacute stage group, 7 patients (35.00\%) were bilateral NAION, which did not differ from the acute stage group ( $P=0.33$ ). The chronic stage group (30 patients) had 22 patients (73.33\%) who suffering the bilateral NAION, which was significantly higher compared with the acute and subacute stage groups $(P<0.01)$.

Table 1: Incidence of bilateral eyes in NAION 


\begin{tabular}{ccccccc}
\hline Patients & Acute & Subacute & Chronic & \multicolumn{3}{c}{$P$ value } \\
\cline { 5 - 7 } & stage (A) & stage (S) & stage (C) & A vs. S & A vs. C & S vs. C \\
\hline Bilateral & $6(20.00 \%)$ & $7(35.00 \%)$ & $22(73.33 \%)$ & 0.3266 & $<0.0001$ & 0.0097 \\
attact & 30 & 20 & 30 & & & \\
Total & 30 & & &
\end{tabular}

\section{Differences in Fundus Findings among different stages of NAION by FP}

FP revealed a significant difference among the progression of NAION (Table 2). The incidence of macular edema decreased with the prolongation of NAION duration (acute stage group, 63.89\%; subacute stage group, $33.33 \%$; chronic stage group, $0.00 \%$, both $P<0.05$ ). The incidence rates of papilloedema in acute and subacute stage groups were $94.44 \%$ and $88.89 \%$ respectively. In addition, it is common to find disc hemorrhage and exudation in acute and subacute stage groups (75.00\% and 55.56\%). However, they disappeared in the chronic stage group. In contrast, optic atrophy almost all appeared in the chronic stage group (94.23\%), which was rare in the acute and subacute stage groups $(0.00 \%$ and $3.70 \%)$.

Table 2: Characteristics of NAION by FP

\begin{tabular}{|c|c|c|c|c|c|c|}
\hline \multirow[t]{2}{*}{ Eyes } & \multirow{2}{*}{$\begin{array}{c}\text { Acute } \\
\text { stage (A) }\end{array}$} & \multirow{2}{*}{$\begin{array}{l}\text { Subacute } \\
\text { stage (S) }\end{array}$} & \multirow{2}{*}{$\begin{array}{l}\text { Chronic } \\
\text { stage (C) }\end{array}$} & \multicolumn{3}{|c|}{$P$ value } \\
\hline & & & & A VS. S & A vs. C & S VS. C \\
\hline Papilloedema & $94.44 \%$ & $88.89 \%$ & $0.00 \%$ & 0.6434 & $<0.0001$ & $<0.0001$ \\
\hline $\begin{array}{l}\text { Disc hemorrhage } \\
\text { and exudation }\end{array}$ & $75.00 \%$ & $55.56 \%$ & $0.00 \%$ & 0.1166 & $<0.0001$ & $<0.0001$ \\
\hline Macular edema & $63.89 \%$ & $33.33 \%$ & $0.00 \%$ & 0.0226 & $<0.0001$ & $<0.0001$ \\
\hline Optic atrophy & $0.00 \%$ & $3.70 \%$ & $94.23 \%$ & 0.4286 & $<0.0001$ & $<0.0001$ \\
\hline
\end{tabular}

\section{Differences in Fundus Findings among different stages of NAION by FA}

FA presented the difference between chronic stage group and others, while there were no significant differences between acute and subacute stage groups (Table 3). Chronic stage group tended to have less macular fluorescence accumulation and peripapillary choroid filling delay $(0.00 \%$ and $3.85 \%, P<0.01)$. However, disc filling defects had higher incidence in chronic stage group (88.46\%) than acute and subacute stage groups $(5.56 \%$ and $7.41 \%, P<0.01)$. Moreover, retinal artery filling delay only appeared in the chronic stage group $(25.00 \%)$.

Table 3: Characteristics of NAION by FA 


\begin{tabular}{|c|c|c|c|c|c|c|}
\hline \multirow[t]{2}{*}{ Eyes } & \multirow{2}{*}{$\begin{array}{c}\text { Acute } \\
\text { stage (A) }\end{array}$} & \multirow{2}{*}{$\begin{array}{l}\text { Subacute } \\
\text { stage (S) }\end{array}$} & \multirow{2}{*}{$\begin{array}{l}\text { Chronic } \\
\text { stage (C) }\end{array}$} & \multicolumn{3}{|c|}{$P$ value } \\
\hline & & & & A VS. S & A vs. C & S VS. C \\
\hline $\begin{array}{c}\text { Macular } \\
\text { fluorescence }\end{array}$ & $25.00 \%$ & $14.81 \%$ & $0.00 \%$ & 0.3654 & 0.0002 & 0.0117 \\
\hline $\begin{array}{c}\text { accumulation } \\
\text { Peripapillary } \\
\text { choroid filling delay }\end{array}$ & $72.22 \%$ & $92.59 \%$ & $3.85 \%$ & 0.0547 & $<0.0001$ & $<0.0001$ \\
\hline Disc filling defects & $5.56 \%$ & $7.41 \%$ & $88.46 \%$ & 1.00 & $<0.0001$ & $<0.0001$ \\
\hline $\begin{array}{l}\text { Retinal artery } \\
\text { filling delay }\end{array}$ & $0.00 \%$ & $0.00 \%$ & $25.00 \%$ & & 0.0006 & 0.0032 \\
\hline
\end{tabular}

\section{Discussion}

NAION is the most common acute optic neuropathy among older people ${ }^{9}$. Anthony $\mathrm{C}$. et al found it is not rare in younger patients aging less than 50 years older. Moreover, the younger patients tent to be more frequent in the fellow eye involvement ${ }^{10}$. The Ischemic Optic Neuropathy Decompression Trial (IONDT) found that $43 \%$ of patients could have a greatly reduced vision within six months in NAION ${ }^{11-13}$. It is beneficial to treat with highdose corticosteriod during the initial stages ${ }^{14}$. Therefore, exploring the clinical features of each stage of NAION for proper treatment is critical.

The prevalence of the other eye in NAION is $12-15 \%$ in 5 years, especially among patients having diabetes ${ }^{15,16}$. Our study found that the risk of involvement of the second eye had a remarkable growth from $20.00 \%$ in a month to $73.33 \%$ in half a year. The pathogenesis of NAION is highly complex, which were hypoperfusion and ischemia of the anterior optic nerve ${ }^{17}$. With the worsen of ischemia, the optic-nerve head became crowding. Edema of optic disc was the most significant fundus performance in the early stage, including macular edema, papilloedema, disc hemorrhage and exudation. At the end stage of NAION development, optic nerve atrophy was the most significant clinical features, during which the recurrence rate of NAION in the affected eye was less than $5 \%^{3}$.

The current FA research of NAION mainly focus on optic nerve head in acute stage. We summarized the related researches in acute stage of NAION among old patients, which was consistent with our research ${ }^{5,10,18}$ (Table 4). There was a decreasing trend in macular fluorescence accumulation among these three groups, though acute and subacute stage groups having no significant difference $(P=0.3654)$. These data could be statistically significant with more cases involved. In the acute stage of NAION, the optic disc is not consistent with the background, showing a quadrant-like distribution in the early FA. However, it had a strong fluorescence in the late stage due to the edema of optic disc. In the chronic stage of NAION, the disc filling defect was the significant feature, which appeared as a deficiency of superficial fluorescence filling in the venous phase. The optic-nerve head receives arterial blood from the posterior ciliary arteries (PCA) mainly, which supplies the posterior part of optic-nerve head. Moreover, the central retinal artery (CRA) supplies the inner retina. The abnormal blood flow of CRA is the further pathological changes in NAION ${ }^{19,20}$. It is consistent with our research that retinal artery filling delay was more common in the chronic stage of NAION.

Table 4: Characteristics of NAION in previous published reports by FA 


\begin{tabular}{cccccccc}
\hline $\begin{array}{c}\text { First } \\
\text { author }\end{array}$ & Year & Location & Eyes & Female & Mean age & $\begin{array}{c}\text { Peripapillary } \\
\text { choroid filling } \\
\text { delay }\end{array}$ & $\begin{array}{c}\text { Disc } \\
\text { filling } \\
\text { defects }\end{array}$ \\
\hline $\begin{array}{c}\text { Present } \\
\text { Min KK }\end{array}$ & 2016 & China & 113 & $60.00 \%$ & $64.26 \pm 8.12$ & $72.22 \%$ & $5.56 \%$ \\
$\begin{array}{c}\text { Anthony } \\
\text { CA }\end{array}$ & 2013 & USA & 23 & $47.83 \%$ & $56.90 \pm 9.40$ & $69.60 \%$ & $56.50 \%$ \\
$\begin{array}{c}\text { Sibel } \\
\text { OTO }\end{array}$ & 2002 & Turkey & 11 & $36.00 \%$ & $>50.00$ & $26.80 \%$ & $53.70 \%$ \\
\hline
\end{tabular}

Nowadays, there are many techniques to diagnose optic neuropathy. However, there were no obvious abnormality in NAION by imaging of the optic-nerve. Sibel OTO found FA performing choriocapillaris better than indocyanine green angiography $(\text { ICGA })^{18}$. Valmaggia reported that ICGA could not provide more details than $\mathrm{FA}^{21}$. David Kuerten et al. combined Colour Doppler Imaging (CDI) and FA to find that disturbed blood flow of CRA was associated with acute NAION ${ }^{22}$. Optical Coherence Tomographic Angiography (OCT-A) has a significant high resolution, which could display the superficial vasculature accurately ${ }^{23}$. In addition, it also has its own limitations $₫$ which could not evaluate the transit time in a dynamic way ${ }^{24}$. Overlying edema and hemorrhage could influence the angiographic signal in OCT-A ${ }^{25}$.

To sum up, our study summarized the different characteristics among the progression of NAION by FP and FA in NAION patients. Identifying their features at different stages could help guiding future therapeutics and improving patient prognosis.

\section{Conclusions}

In summary, our study demonstrated that different stages of NAION had its own characteristics. For FP part, the acute and subacute stage tends to have macular edema, papilloedema, disc hemorrhage and exudation. Moreover, they showed macular fluorescence accumulation and peripapillary choroid filling delay more, instead of retinal artery filling delay and disc filling defects compared with the chronic stage. These findings may help us understanding the the mechanisms of NAION pathogenesis better for accurate diagnosis and treatment.

\section{Abbreviations}

NAION: Non-arteritic anterior inschemic optic neuropathy; FP: Fundus photography; FA: Fluorescein aniography; ON: Optic neuritis; AION: Arteritic anterior ischemic optic neuropathy; IONDT: Ischemic optic neuropathy decompression trial; PCA: Posterior ciliary arteries; CRA: Central retinal artery; ICGA: Indocyanine green angiography; $\mathrm{CDI}$ : Colour doppler imaging; OCT-A: Optical coherence tomographic angiography

\section{Declarations}

\section{Acknowledgments}

None.

Funding 
No funding was received by neither of authors.

\section{Availability of data and materials}

Not applicable, same reasoning.

\section{Authors' contributions}

Analysis and interpretation of data, preparation and review the manuscript (LP W); Design of the study, collection and management of data $(\mathrm{Y} L)$. Both of authors read and approved the final manuscript.

\section{Competing Interests}

None.

\section{Consent for publication}

Not applicable.

\section{Ethics approval and consent to participate}

This study received ethical approval from institutional ethics committee of People's Liberation Army General Hospital (PLAGH) in accordance with the Helsinki Declaration. A written informed consent was obtained from patients in this study.

\section{Publisher's Note}

Springer Nature remains neutral with regard to jurisdictional claims in published maps and institutional affiliaions.

\section{Author details}

Department of Ophthalmology, The First Affiliated Hospital of Chinese People's Liberation Army General Hospital, Beijing, China

\section{References}

1 Lee, M. S., Grossman, D., Arnold, A. C. \& Sloan, F. A. Incidence of nonarteritic anterior ischemic optic neuropathy: increased risk among diabetic patients. Ophthalmology 118, 959-963, doi:10.1016/j.ophtha.2011.01.054 (2011).

2 Yang, H. K. et al. Obstructive sleep apnoea and increased risk of non-arteritic anterior ischaemic optic neuropathy. Br J Ophthalmol, doi:10.1136/bjophthalmol-2018-312910 (2018).

3 Biousse, V. \& Newman, N. J. Ischemic Optic Neuropathies. N Engl J Med 372, 2428-2436, doi:10.1056/NEJMra1413352 (2015). 
Hayreh, S. S. Ischemic optic neuropathies - where are we now? Graefes Arch Clin Exp Ophthalmol251, 1873-1884, doi:10.1007/s00417-013-2399-z (2013).

$5 \quad$ Kim, M. K. \& Kim, U. S. Analysis of Fundus Photography and Fluorescein Angiography in Nonarteritic Anterior Ischemic Optic Neuropathy and Optic Neuritis. Korean J Ophthalmo/30, 289-294, doi:10.3341/kjo.2016.30.4.289 (2016).

6 Arnold, A. C., Badr, M. A. \& Hepler, R. S. Fluorescein angiography in nonischemic optic disc edema. Arch Ophthalmol 114, 293-298 (1996).

7 Shin, S. Y., Kim, D. S. \& Ko, M. K. Fluorescein angiographic features of choroidal insufficiency in anterior ischemic optic neuropathy. Korean J Ophthalmol 13, 100-104, doi:10.3341/kjo.1999.13.2.100 (1999).

8 Soltanipour, A., Sadri, S., Rabbani, H. \& Akhlaghi, M. R. Analysis of Fundus Fluorescein Angiogram Based on the Hessian Matrix of Directional Curvelet Sub-bands and Distance Regularized Level Set Evolution. $J$ Med Signals Sens 5, 141-155 (2015).

9 Zorrilla-Vaca, A. et al. Acute Kidney Injury Following Acute Ischemic Stroke and Intracerebral Hemorrhage: A Meta-Analysis of Prevalence Rate and Mortality Risk. Cerebrovasc Dis 45, 1-9, doi:10.1159/000479338 (2018).

10 Arnold, A. C., Costa, R. M. \& Dumitrascu, O. M. The spectrum of optic disc ischemia in patients younger than 50 years (an Amercian Ophthalmological Society thesis). Trans Am Ophthalmol Soc 111, 93-118 (2013).

11 Arnold, A. C. Ischemic optic neuropathy. In: Miller NR, Newman NJ, eds. Walsh \& Hoyt's Clinical NeuroOphthalmology Vol 1.6th ed. Phiadelphia, PA: Lippincott Williams \& Wilkins; 2005: 349-384 (2005).

12 Ischemic Optic Neuropathy Decompression Trial: twenty-four-month update. Arch Ophthalmo/118, 793-798 (2000).

13 Characteristics of patients with nonarteritic anterior ischemic optic neuropathy eligible for the Ischemic Optic Neuropathy Decompression Trial. Arch Ophthalmol 114, 1366-1374 (1996).

14 Hayreh, S. S. \& Zimmerman, M. B. Non-arteritic anterior ischemic optic neuropathy: role of systemic corticosteroid therapy. Graefes Arch Clin Exp Ophthalmol 246, 1029-1046, doi:10.1007/s00417-008-0805-8 (2008).

15 Newman, N. J. et al. The fellow eye in NAION: report from the ischemic optic neuropathy decompression trial follow-up study. Am J Ophthalmol 134, 317-328 (2002).

16 Preechawat, P., Bruce, B. B., Newman, N. J. \& Biousse, V. Anterior ischemic optic neuropathy in patients younger than 50 years. Am J Ophthalmol 144, 953-960, doi:10.1016/j.ajo.2007.07.031 (2007).

17 Hayreh, S. S. Posterior ischaemic optic neuropathy: clinical features, pathogenesis, and management. Eye (Lond) 18, 1188-1206, doi:10.1038/sj.eye.6701562 (2004). 
18 Oto, S., Yilmaz, G., Cakmakci, S. \& Aydin, P. Indocyanine green and fluorescein angiography in nonarteritic anterior ischemic optic neuropathy. Retina 22, 187-191 (2002).

19 Kaup, M., Plange, N., Arend, K. O. \& Remky, A. Retrobulbar haemodynamics in non-arteritic anterior ischaemic optic neuropathy. Br J Ophthalmol 90, 1350-1353, doi:10.1136/bjo.2006.093559 (2006).

20 Leiba, H. et al. Optic nerve head blood flow measurements in non-arteritic anterior ischaemic optic neuropathy. Eye (Lond) 14, 828-833, doi:10.1038/eye.2000.231 (2000).

21 Valmaggia, C., Speiser, P., Bischoff, P. \& Niederberger, H. Indocyanine green versus fluorescein angiography in the differential diagnosis of arteritic and nonarteritic anterior ischemic optic neuropathy. Retina $19,131-134$ (1999).

22 Kuerten, D., Fuest, M., Bienert, M. \& Plange, N. Retrobulbar and intraocular blood flow in anterior ischaemic optic neuropathy are linked to the functional impairment. Int Ophthalmol 39, 597-604, doi:10.1007/s10792-018-0846-x (2019).

23 Spaide, R. F., Klancnik, J. M., Jr. \& Cooney, M. J. Retinal vascular layers imaged by fluorescein angiography and optical coherence tomography angiography. JAMA Ophthalmo/ 133, 45-50, doi:10.1001/jamaophthalmol.2014.3616 (2015).

24 Cestari, D. M. et al. Demographic, Systemic, and Ocular Factors Associated with Nonarteritic Anterior Ischemic Optic Neuropathy. Ophthalmology 123, 2446-2455, doi:10.1016/j.ophtha.2016.08.017 (2016).

25 Gaier, E. D. et al. Quantitative analysis of optical coherence tomographic angiography (OCT-A) in patients with non-arteritic anterior ischemic optic neuropathy (NAION) corresponds to visual function. PLoS One 13, e0199793, doi:10.1371/journal.pone.0199793 (2018). 